\title{
Cryopreservation of the Trachea Can Reduce Its Antigenicity in Various Species
}

\author{
Arpad Juhasz ${ }^{1,2}$, Norbert Lippai ${ }^{3}$, Agnes Novak ${ }^{3}$, Ibolya Szekeres³, Sumeet K. Mittal2, \\ Aron Altorjay 1 \\ ${ }^{1}$ Department of Surgery, St George University Teaching Hospital, Szekesfehervar, Hungary \\ ${ }^{2}$ Department of Surgery, Creighton University Medical Center, Omaha, USA \\ ${ }^{3}$ Department of Pathology, Geza Hetenyi County Hospital, Szolnok, Hungary \\ Email: "juhasz.arpadimre@gmail.com
}

Received 23 April 2015; accepted 17 May 2015; published 21 May 2015

Copyright (C) 2015 by authors and Scientific Research Publishing Inc.

This work is licensed under the Creative Commons Attribution International License (CC BY).

http://creativecommons.org/licenses/by/4.0/

(c) (i) Open Access

\section{Abstract}

Background: Cryopreserved tracheal allograft has been used successfully for esophageal replacement in the canine model. The working hypothesis was cryopreservation decreases antigenicity but epithelial desquamation remains. However, cryopreservation of human tracheal samples collected at tracheostomy, resulted in no significant desquamation. The aim of this study was to examine the extent of desquamation of the epithelial layer of cryopreserved animal tracheas and find a reason for decreased antigenicity of cryopreserved canine and pig's trachea. Methods: $\mathbf{5} \mathbf{~ c m}$ long tracheal segments were removed from 6 dogs and 125 pigs and stored in liquid nitrogen for 21 days. Cross section samples were taken from the end of the segment, $1 \mathrm{~cm}$ from the end and at the middle of the segment. Histological examination was performed using haematoxyllin-eosin and MHC-II antigen specific antibody staining. Changes in histological structure were analyzed. Results: General histological morphology of samples changed after cryopreservation. The percentage of intact epithelium and the overall intensity of immune-staining increased significantly from the ends to the middle of the segments, but the intensity of immune-staining showed no difference in the remaining epithelial cells. Conclusion: Cryopreservation damages the epithelial cells, but does not influence the cell's antigenicity or cause desepithelisation. The main effect is a retraction of the epithelial layer from the ends to the midpart and this effect may be protection against organ rejection. Based on our canine and pig results a $5 \mathrm{~cm}$, long tracheal segment seems to be a promising organ for human esophageal replacement.

\section{Keywords}

Cryopreservation, Trachea Transplantation, Esophagus Replacement

\footnotetext{
${ }^{*}$ Corresponding author.
}

How to cite this paper: Juhasz, A., Lippai, N., Novak, A., Szekeres, I., Mittal, S.K. and Altorjay, A. (2015) Cryopreservation of the Trachea Can Reduce Its Antigenicity in Various Species. Open Journal of Gastroenterology, 5, 31-36. 


\section{Background}

Esophageal resection is a common surgical operation. To secure the continuity of the intestinal tract the resected organ has to be replaced. Except when a short segment resection is performed stomach, small intestine or the colon are routinely used organs for replacement. In rare cases, the organ chosen for the replacement is too short. To bridge this hiatus, cryopreserved tracheal allograft has been used successfully in a previous canine model [1]. Japanese researchers performed previously successful tracheal allo-transplantation using cryopreserved grafts in rat and canine models also [2] [3]. Our working hypothesis-based on results of Aoki and Toyo-was desquamation of the epithelial layer is associated with decreased antigenicity during cryopreservation. However-as a new step-cryopreservation of human tracheal samples collected at tracheostomy, resulted in no significant desquamation. The aim of this study was to examine the extent of desquamation of the epithelial layer of cryopreserved animal tracheas and find a reason for decreased antigenicity of cryopreserved organs using canine (prephase study) and pig's trachea.

\section{Methods}

After IRB approval, under sterile conditions a $5 \mathrm{~cm}$. long tracheal segment was removed from 6 euthanized dogs (pre-phase study) and from 125 pigs. Pigs used for research are the most ideal animals; sizes of organs are large enough to handle them easily, quality of tissues seems like human tissues. Five pig samples were used as a control, the other 120 pig and the dog samples were stored in liquid nitrogen $\left(-196^{\circ} \mathrm{C} /-321^{\circ} \mathrm{C}\right.$ respectively) for 21 days. After warm-up, circular samples were taken from the end of the graft (Sample A), $1 \mathrm{~cm}$ from the end (Sample B) and from the middle of the graft (Sample C). Each paraffin banded sample was stained using haematoxylin-eosin (HE) and for immunological examination using MHC-II antigen specific antibody (HLA class II (DR)(NCL-LN3) antigen ${ }^{\circledR}$; Novocastra Ltd., Newcastle Upon Tyne, UK). In each sample, the inner circumference and the thickness of epithelial layer was measured.

Based on initial results of the canine-model the pig samples were analyzed to compare the quality of the epithelial layer. The samples were divided into three sub-groups (SG); $\mathrm{SG}_{1}$ ) intact or near intact epithelial layer with a well-structured tunica mucosa; $\mathrm{SG}_{2}$ ) epithelial layer with a loose sub-mucosa but without mucosa and $\mathrm{SG}_{3}$ ) a naked peri-chondrium without a visible sub-mucosal layer. In each subgroup the percentage of inner circumference was calculated and compared.

In each sample of 100 epithelial cells, if found, the total number of MHC-II antigen positive (stained) cells was calculated and compared. The intensity of immuno-histological staining in the stained epithelial cells was ranked as,+++ or +++ . Cryopreservation cannot influence the MHC-II presentation of lymphocytes, therefore it's staining intensity was assigned as +++ in samples. It means the immuno-histological staining intensity of epithelial layer was auto-controlled creating comparable results. Analysis (SPSS Statistics $17^{\circledR}$; IBM, Chicago, IL, USA) was used to compare the results using Chi-square-test $(\mathrm{p}<0.005)$ and Kruskal-Wallis-test $(\mathrm{p}<0.005)$.

\section{Results}

Pre-phase-canine model: Intact epithelium in samples A, B and C was found in 0\%, 33\% and 100\% of cases. Lack of an epithelial layer was found in 53\%, 34\% and 10\% of A, B and C circumferential samples respectively. Similarly immunstaining showed a significant decrease in intensity from mid to the end graft portion and this corresponded with the loss of the epithelial layer.

Pig-model: In the cryopreserved samples compared to control the epithelial cells were more compact and cuboid and the intercellular connections seemed to be weak. In the control tracheas, the ratio of epithelial layer and lamina propria-submucosa was 1:5, however, the ratio in the cryopreserved samples was 1:12. The reason was the extremely loose sub-mucosal connective tissue (Figure 1). The tracheal cartilage was intact in all samples. Totally intact circumferential epithelium was found in 0/120 cases in Sample A, in 6/120 cases in Sample B and in 28/120 cases in Sample C. The inner circumference was $60.9 \mathrm{~mm}$ on average for all cases. From Samples A to Samples C, a significant decrease was seen in percentage of SG1 and a significant increase in percentage of SG3 was found (Table 1, Figure 2). The number of MHC-II positive cells in the remaining epithelial layer showed a significant increase from the end to the midpart of the graft (Table 2). In the slides, the overall intensity of immune-staining decreased from the end to the midpart of grafts and the staining intensity of MHC-II positive cells was equal in all locations (Table 3). 


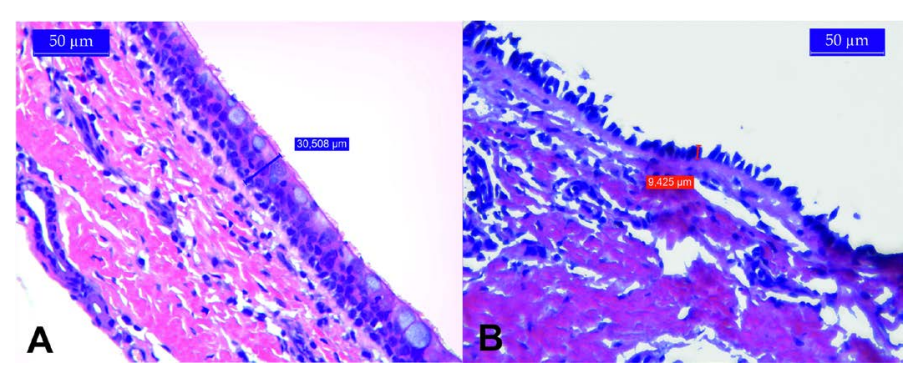

Figure 1. (A) Pig's trachea without cryopreservation (HE, 40×); (B) Pig's trachea after cryopreservation (HE, 40×).

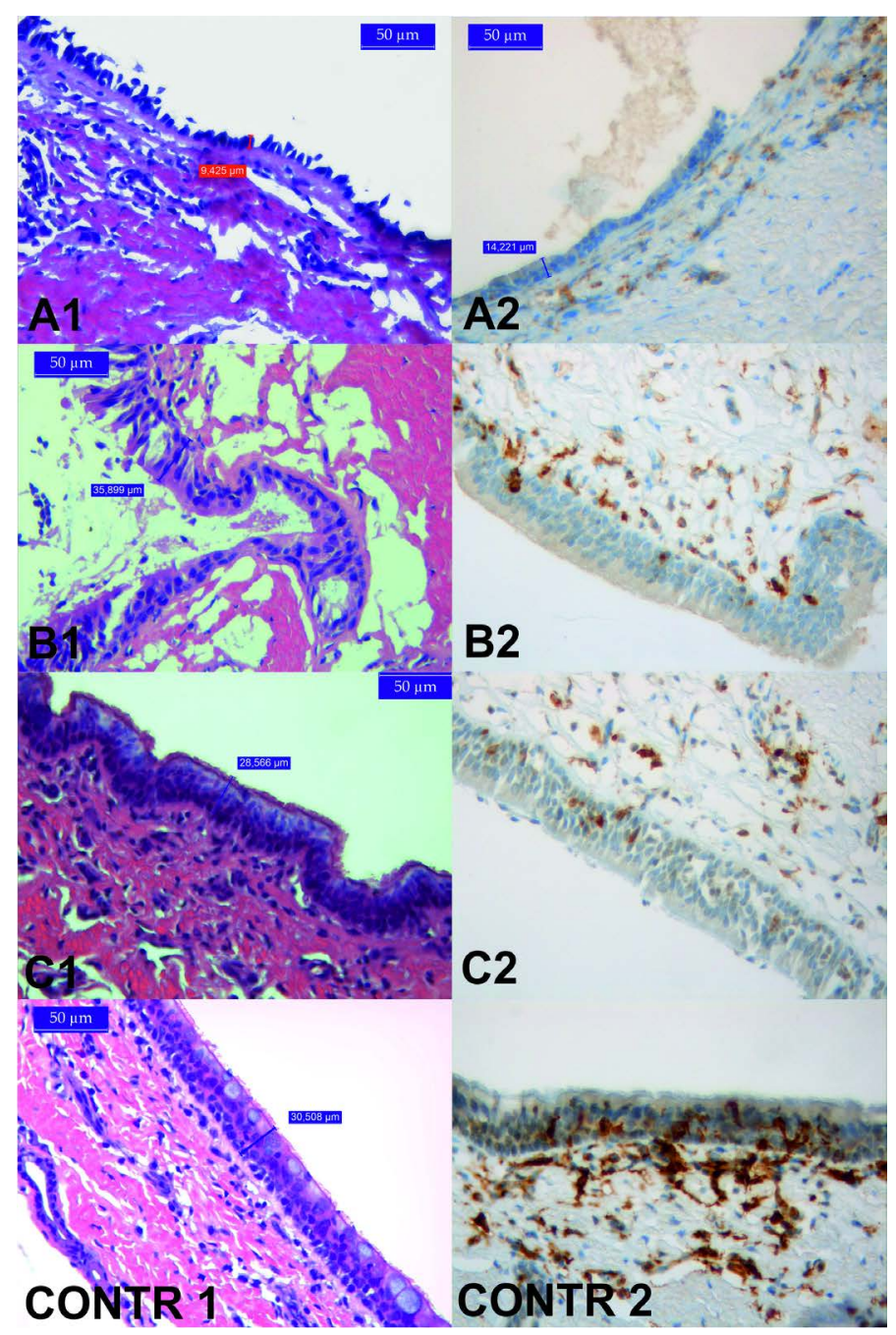

Figure 2. Pig's trachea in sample A (A1-HE, 40×; A2-MHC-II specific antibody staining, 40×), B (B1-HE, 40×; B2-MHC-II specific antibody staining, 40×), C (C1-HE, 40×; C2-MHC-II specific antibody staining, 40×) and in controll sample (Contr 1-HE, 40×; Contr 2-MHC-II specific antibody staining, 40×).

\section{Discussion}

The aim of this study was to examine the effect of cryopreservation on a $5 \mathrm{~cm}$ long animal trachea segment and its changes of antigenicity. Our results verified desepithelisation at the ends of the trachea, but quite normal epi- 
Table 1. Changes in quality of epithelial layer in percentage of inner perimeter in samples (Chi-square-test).

\begin{tabular}{cccc}
\hline & \multicolumn{2}{c}{ Percentage of intact epithelial layer (SG1) in samples } & \\
\hline & mean & SD & \\
Sample A & 38.43 & 27.8 & A vs B: 0.722 \\
Sample B & 39.84 & 31.14 & A vs C: $\mathbf{0 . 0 0 0 3}$ \\
Sample C & 54.85 & 36.88 & B vs C: $\mathbf{0 . 0 0 1 9}$ \\
& Percentage of epithelial layer with a loose sub-mucosa but without mucosa (SG2) & \\
Sample A & 19.29 & 16.23 & A vs B: 0.1452 \\
Sample B & 22.99 & 18.22 & A vs C: 0.1894 \\
Sample C & 15.8 & 20.28 & B vs C: $\mathbf{0 . 0 1 4 5}$ \\
& Percentage of naked peri-chondrium without a visible sub-mucosal layer (SG3) & \\
Sample A & 42.01 & 29.19 & A vs B: 0.2451 \\
Sample B & 37.41 & 30.08 & A vs C: $\mathbf{0 . 0 0 3 1}$ \\
Sample C & 29.35 & 30.93 & B vs C: $\mathbf{0 . 0 1 4 5}$ \\
\hline
\end{tabular}

Table 2. Mean number of MCH-II positive cells in the remaining epithelial layer in samples (Kruskal-Wallis test).

\begin{tabular}{rcccc}
\hline & Mean number of MHC-II positive cells in the remining epithelial layer in samples & $p$-value \\
\hline Sample A & mean & SD & 5.73 & A vs B vs C: $<\mathbf{0 . 0 0 0 1}$ \\
Sample B & 28.2 & 5.16 & \\
Sample C & 41 & 4.24 & \\
\hline
\end{tabular}

Table 3. Mean intensity of MCH-II specific antibody staining in samples (Kruskal-Wallis test).

\begin{tabular}{|c|c|c|}
\hline \multicolumn{3}{|c|}{ Mean intensity of immunostaining in samples } \\
\hline & mean & $p$-value \\
\hline Sample A & 1.64 & \\
\hline Sample B & 1.95 & A vs B vs C: 0.6977 \\
\hline Sample C & 1.75 & \\
\hline
\end{tabular}

thelium in the midpart of the graft after cryopreservation. The thickness of the epithelial layer and the number of immunstained epithelial cells decreased at the specimen ends. However, the intensity of epithelial cell immune-staining showed no difference in samples. It means the total number of epithelial cells decrease from the ends to the midpart of the graft, but cryopreservation does not directly influence the MHC-II antigen in the remaining epithelial cells. We hypothize that cryopreservation damaged the visible remaining epithelial cells (the cell's morphology altered as mentioned above), but an effective decrease of antigenicity requires the lack of epithelial cells.

Our intention is to find an alternative for short segment esophageal replacement, when the conventional organs (stomach, jejunum, large intestine) are not feasible for replacement. Various methods have been evaluated for replacement, with questionable results to date [4]-[9]. In a previous canine investigation a 5-cm-long esophageal segment was successfully replaced using a tracheal allograft [1]. In organ transplantation the main problem is organ-rejection. The MHC-II antigen presenting cells are located on the dendritic cells, phagocytes, lym- 
phocytes and on some endothelial cells also. This endothelial presentation is responsible for acute and chronic rejection of grafts [10] [11]. Rossi et al. verified MHC-II antigens on the inner epithelial layer of the trachea [12]. This antigen is suggested as the main reason for tracheal antigenicity [13]. Researchers have shown that cryopreservation will reduce the number of MHC-II antigens and antigenicity of the trachea [3]. To avoid graftversus-host reaction the tracheal grafts were cryopreserved for 21 days in liquid nitrogen prior to implantation. We believed our success was based on cryopreservation creating desquamation of the inner epithelial layer and decreasing its antigenicity. As a next step we investigated the human trachea: whole thinkness $1 \mathrm{~cm}^{2}$ human trachea samples were removed at tracheostomy and cryopreserved. The results were contrary to our expectations, the cryoprecipitation did not cause any desquamation of the epithelial layer.

Our results account for the success of esophageal replacement in a canine model using a tracheal graft or the lack of success on examination of human tracheal samples. Cryopreservation of a tubular trachea specimen damages the epithelial layer, however, the main effect is retraction of epithelium from the ends to the midpart, and neo-vascularisation of a transplanted trachea starts at the ends of the segment [14]. At the time of regeneration the recipient-like epithelium is not in contact with the donor epithelium because of retraction. Later, when neo-epithelisation is complete the donor-like epithelium in the midpart desquamated because of relative tissue hypoxia. That is why we had no graft rejection after trachea transplantation. In addition the $5 \mathrm{~cm}$ transplantable tracheal sample is not only the maximum [15], but the optimal length. However, our results are not species-specific, we found the same in canine and pig specimens as well.

Esophageal replacement using extraintestinal materials is challenging. A stem-cell-based, tissue engineered successful tracheal transplantation was published in 2012 [16]. The result was promising, however, the method was complicated. Our results are based on an easier method. We plan to collect and examine 5-cm-long human tracheal samples from organ donors. If we have the same results, a donor-tissue bank will be created, to replace small esophageal segment gaps in selected cases.

\section{Acknowledgements}

The authors are grateful for the opportunity given to them to make the histological examinations in the Department of Pathology of Geza Hetenyi County Hospital, Szolnok, Hungary. We also thank Charles J Filipi MD, FACS for critical reading of the manuscript before its submission.

\section{Conflict of Interest}

The authors disclose no conflicts.

\section{References}

[1] Juhász, Á., Szilágyi, A., Mikó, I., et al. (2008) Esophageal Replacement Using Cryopreserved Tracheal Graft. Diseases of Esophagus, 21, 468-472. http://dx.doi.org/10.1111/j.1442-2050.2007.00780.X

[2] Aoki, T., Yamato, Y., Tsuchida, M., Souma, T., Yoshiya, K., Watanabe, T. and Hayashi, J. (1999) Succesful Tracheal Transplantation Using Cryopreserved Allografts in a Rat Model. European Journal of Cardio-Thoracic Surgery, 16, 169-173. http://dx.doi.org/10.1016/S1010-7940(99)00145-1

[3] Toyo, T., Niwaya, K., Sawabata, N., Kushibe, K., Nezu, K., Taniuchi, S. and Kitamura, S. (1998) Tracheal Replacement with Cryopreserved Tracheal Allograft—Experiment in Dogs. The Annals of Thoracic Surgery, 66, 209-213. http://dx.doi.org/10.1016/S0003-4975(98)00270-7

[4] Gonzale Saez, L.A., Arnal Monreal, F., Pita Fernandez, S. and Machuca Sabta Cruz, J. (2003) Experimental Study Using PTFE (Goretex) Pathes for Replacement of the Oesophageal Wall. European Surgical Research, 35, 372-376. http://dx.doi.org/10.1159/000070609

[5] Takimoto, Y., Nakamura, T., Yamamoto, Y., Kiyotani, T., Teramachi, M. and Shimizu, Y. (1998) The Experimental Replacement of a Cervical Esophageal Segment with an Artificial Prosthesis with the Use of Collagen Matrix and a Silicone Stent. Journal of Thoracic and Cardiovascular Surgery, 116, 98-106. http://dx.doi.org/10.1016/S0022-5223(98)70247-8

[6] Natsume, T., Ike, O., Okada, T., Takimoto, N. and Shimizu, Y. (1993) Porous Collagen Sponge for Esophageal Replacement. Journal of Biomedical Materials Research, 27, 867-875. http://dx.doi.org/10.1002/jbm.820270705

[7] Natsume, T., Ike, O., Okada, T., Shimizu, Y. and Ikada, Y. (1990) Experimental Studies of a Hybrid Artificial Esophagus Combined with Autologous Mucosal Cells. ASAIO Transactions, 36, M435-M437. 
[8] Salomon, J., Nudelman, I., Kissin, L., Gassner, S. and Levy, M.J. (1977) Experimental Segmental Replacement of Esophagus by Biological Tissues. Israel Journal of Medical Sciences, 13, 272-277.

[9] Yamamoto, Y., Nakamura, T., Shimizu, Y., Matsumoto, K., Takimoto, Y., et al. (1999) Intrathoracic Esophageal Replacement in the Dog with the Use of an Artificial Esophagus Composed of a Collagen Sponge with a Double-Layered Silicone Tube. The Journal of Thoracic and Cardiovascular Surgery, 118, 276-286. http://dx.doi.org/10.1016/S0022-5223(99)70218-7

[10] Jaramillo, A., Fernandez, F.G., Kuo, E.Y., et al. (2005) Immune Mechanisms in the Pathogenesis of Bronchiolitis Obluterans Syndrome after Lung Transplantation. Pediatric Transplantation, 9, 84-93. http://dx.doi.org/10.1111/j.1399-3046.2004.00270.x

[11] Belperio, J.A., Weigt, S.S., Fishbein, M.C., et al. (2009) Chronic Lung Allograft Rejection: Mechanisms and Therapy. Proceedings of the American Thoracic Society, 16, 108-121. http://dx.doi.org/10.1513/pats.200807-073GO

[12] Rossi, G.A., Sacco, O., Balbi, B., et al. (1990) Human Ciliated Bronchial Epithelial Cells: Expression of the HLA-DR Antigens and of the HKA-DR Alpha Gene, Modulation of the HLA-DR Antigens by Gamma-Interferon and AntigenPresenting Function in the Mixed Leukocyte Reaction. American Journal of Respiratory Cell and Molecular Biology, 3 , 431-439. http://dx.doi.org/10.1165/ajrcmb/3.5.431

[13] Buija, J., Wilmes, E., Hammer, C. and Kasternbauer, E. (1990) Tracheal Transplantation: Demonstration of HLA Class II Subregion Gene Products on Human Trachea. Acta Otolaryngology, 110, 149-154. http://dx.doi.org/10.3109/00016489009122530

[14] Moriyama, H., Sasajima, T., Hirata, S., et al. (2000) Revascularization of Canine Cryopreserved Tracheal Allografts. Annals of Thoracic Surgery, 69, 1701-1706. http://dx.doi.org/10.1016/S0003-4975(00)01297-2

[15] Grillo, H.C. (1990) Tracheal Replacement. Annals of Thoracic Surgery, 49, 864-865. http://dx.doi.org/10.1016/0003-4975(90)90857-3

[16] Elliot, M.J., De Coppi, P., Speggiorin, S., Roebuck, D., Butler, C.R., Samuel, E., Crowley, C., McLaren, C., Fierends, A., Vondrys, D., Cochrane, L., Jephson, C., Janes, S., Beaumont, N.J., Cogan, T., Bader, A., Seifalian, A.M., Hsuan, J.J., Lowdell, M.W. and Birchall, M.A. (2012) Stem-Cell-Based, Tissue Engineered Tracheal Replacement in a Child: A 2-Year Follow-Up Study. Lancet, 380, 994-1000. http://dx.doi.org/10.1016/S0140-6736(12)60737-5 